\title{
Grey Decision-Making Method Based on Evidence Theory to Optimize Schemes of Water Resources Allocation
}

\author{
F.P. Wu ${ }^{1}$, L.N. Zhang ${ }^{*}, 1$ L.P. Feng ${ }^{2}$ and P. Jia ${ }^{1}$ \\ ${ }^{1}$ Business School of Hohai University, Nanjing, 210098, P.R. China \\ ${ }^{2}$ Business School of Hohai University (Changzhou), 213022, P.R. China
}

\begin{abstract}
In view of the characteristics of multi-objective and uncertainty and complexity of the water resources allocation, the optimization of water resources allocation schemes can be regarded as a multi-objective grey relational decision-making procedure. This paper, integrating the grey relational decision-making method and the evidence theory, researches on the optimization method of allocation schemes and proposes the grey relational decision-making method based on the evidence theory, wherein the evidence theory is used to excavate the information contained in the decision targets and the weight of each decision target is obtained by the distance function. Then, the grey relational decisionmaking method is applied to calculate the grey relational degree between the weighted situation vectors of the decision targets and the optimal weighted ideal vector of the decision targets based on the grey relational analysis (GRA), and the optimal scheme (or schemes) with the highest grey relational degree from the alternatives is obtained. Finally, we take the optimization of water resources allocation schemes of Tianjin city in China for instance to demonstrate the practicability and effectiveness of this method.
\end{abstract}

Keywords: Grey relational analysis, grey relational decision-making, evidence theory, water resources allocation.

\section{INTRODUCTION}

It is increasingly conscious the water resources allocation in catchments using a combination of both hydrological and economic tools as the demand for water is growing and the supply is not enough to meet this growth [1]. Especially in China, this problem, such as the explosion of urban population, uneven distribution of water resources in time and space, water contamination, low efficiency of water utilization etc., becomes more serious. Water resources may even restrict the social and economic development of an area seriously. Consequently, proper allocation and effective regulation of water resources are the key to realize sustainable utilization of regional water resources and virtuous loop of eco-environment and sustainable development of society and economy [2].

Water resources allocation is a process of making multiobjective decision [3-6]. Meanwhile, in view of the characteristics of multi-objective and uncertainty and complexity of the water resources allocation, we can regard the selection of the proper water resources allocation scheme as a comprehensive decision for a multi-objective scheme under the condition of uncertainty. Some experts and scholars proposed different methods in this area. Wang et al. [7] applied the method of analytic hierarchy process (AHP) to calculate the weight of the indexes of water resources allocation schemes. Guo et al. [8] applied the fuzzy matter-

*Address correspondence to this author at the Business School of Hohai University, Nanjing, 210098, P.R. China; Tel: 025-58099312;

Fax: 025-86902496; E-mail: linazhangv@163.com element model to evaluate the alternatives of water resources allocation of water supply area of south-to-north water transfer project in Hebei province in China. Yu et al. [9] proposed a model combining the fuzzy theory and the information entropy theory to select the optimal deployment of water resources. Dong et al. [2] compounded the value of different target attributes of the same project by the modified Dempster-Shafer evidence theory, and obtained the rank of alternatives of water resources allocation. Zhang et al. [10] proposed the grey clustering evaluation method based on the compact-center-point triangular whitenization weight function (CCTWF), and applied it in the evaluation of water rights allocation scheme. However, there are some limitations for the above mentioned methods. AHP and fuzzy comprehensive evaluation over-dependent on expert decision which makes the result is of a little subjective to some extent. The grey clustering evaluation method on the basis of CCTWF is effective for evaluating a scheme, but usually not for selecting the optimal deployment from several schemes. Although the traditional decision-making methods of scheme optimization have been used widely in studying uncertainty and complexity phenomena, there are still some limitations. These methods especially weight determination method focus too much on the expertise.

While modified Dempster-Shafer evidence theory can be used in the field of multi-source information fusion, there is no agreed-upon standard to allocate the conflict information with high proportion, which may affect the result to a great extent. Evidence theory is an important method in uncertainty reasoning. Based on data processing and data integration of unknown information, it can effectively solve 
the less precise problem caused by fuzziness and uncertainty of the information, and has the good extension and the better classified accuracy. Evidence theory needs no prior probability distributing knowledge of measurement data, and has clear concept and simple calculation [11]. The advantage of evidence theory in data processing and data integration can help determine the weight of each index on the basis of evidence distance.

Grey relational decision-making is a method combining both general decision-making model and grey relational analysis (GRA), which focuses on studying the optimal selection of schemes which only contain part of samples or poor information. The main procedure of the grey relational decision-making is to calculate the grey relational degree between the ideal project and the existing alternatives on the basis of GRA. According to the rank of the results of the grey relational degree, we select the optimal project with the highest grey relational degree from the alternatives [12]. This decision-making method has been successfully applied in various fields. $\mathrm{Wu}[13]$ proposed the grey relational analysis method for 2-tuple linguistic multiple attribute group decision making with incomplete weight information. Chang et al. [14] integrated GRA and the decision-making trial and evaluation laboratory method, to rank the risk of failure, wherein the GRA is used to modify the risk priority number values to lower duplications and the ordered weighted rule is followed.

Hence, based on the previous researches, this paper proposes the grey relational decision-making method based on evidence theory, integrating the evidence theory and the grey relational decision-making method, wherein the evidence theory is used to determine the weight of each decision target and the grey relational decision-making method is applied to determine the optimal scheme (or schemes). In order to prove the practicability of this method, we choose the optimal scheme by mining the contained information of the schemes and considering the social and economic status of Tianjin city in China. The rest of this paper is organized as follows: the next section briefly introduces the overview and some basic concepts of the evidence theory and the grey relational decision-making method, which are relevant to the grey relational decisionmaking method based on the evidence theory in Section 3. In Section 3, we propose the grey relational decision-making method based on evidence theory. In Section 4, the new method is applied to get the optimal scheme of water resources allocation of Tianjin to demonstrate its feasibility and practicability. The final section concludes by discussing our finding.

\section{RALATED WORK}

\subsection{Evidence Theory Overview}

Dempster-Shafer evidence theory is a mathematical tool which was developed in the 1960s for handling under or inexact information $[15,16]$, and later extended and formalized by Shafer [17]. Murphy [18] proposed an improved model based on the primary combination rule by averaging the basic probability assignments (BPAs).
Jousselme et al. [19] proposed distance functions for quantifying the similarity between two sets. Yang et al. [20] introduced the concept of similarity coefficient into evidence theory and constructed a model for the reliability of evidences. A modified average method to combine belief function based on distance measures of evidence is proposed to define evidence weights, and the weight of each body of evidence (BOE) is taken into account [21]. However, it merely makes the evidences simply averaged and does not involve the correlation among different evidences [22], which may result in the situation that the whole fusion process is extensively affected by rare data with great deviation. Hence, we need to determine the correlation among the evidences. Guo et al. [22] summarized the advantage of distance functions and reliability algorithm, and proposed a new combination approach which involves an algorithm of expected support of evidences based on distance functions.

Based on the studies and summarizations of the previous researches, this paper further improves the algorithm of reliability of indexes, and converts the original reliability of indexes into corresponding weights of indexes, which provides necessary data for the next step of the optimization of water resources allocation schemes.

\subsection{Grey Relational Decision-Making Method Overview}

Grey system theory [23-25] is one of the methods used to study uncertainty problems with a small number of samples and incomplete information. The grey system theory includes six major components: grey generating, GRA, grey model, grey prediction, grey decision-making, and grey control. Grey relational decision-making method, based on the GRA, is a very popular method to make decisions in multi-objective situation. It has been successfully applied in solving a variety of multi-objective decision problems [24, 26-30]. Then, to better illustrate the grey relational decisionmaking method on the basis of the evidence theory, we introduce some basic concepts related to the grey relational decision-making method.

Definition 2.1 [12] Let $A=\left\{a_{i} \mid i=1,2, \cdots, r\right\}$ be event set, and $B=\left\{b_{i} \mid i=1,2, \cdots, \mathrm{t}\right\} \quad$ strategy set, if $S=A \times B=\left\{s_{i j}=\left(a_{i}, b_{j}\right) \mid a_{i} \in A, b_{j} \in B\right\}$, then $S$ is called situation set. Let $O=\left\{O_{1}, O_{2}, \cdots, O_{n}\right\}$ be the decision target set, $u_{i j}^{(k)}$ be the effect value of different situations $s_{i j}$ to decision target $k, U_{i j}^{(k)}$ be a mapping from $S \rightarrow R$ with $U_{i j}^{(k)}\left(s_{i j}\right)=u_{i j}^{(k)}$, then we call it an effect mapping of $S$ to target $k$. Note

$u^{(k)}=\left(u_{11}^{(k)}, u_{12}^{(k)}, \cdots, u_{1 t}^{(k)} ; u_{21}^{(k)}, u_{22}^{(k)}, \cdots, u_{2 t}^{(k)} ; \cdots ; u_{r 1}^{(k)}, u_{r 2}^{(k)}, \cdots, u_{r t}^{(k)}\right)$, $k=1,2, \cdots, n$ is the effect sequence of different situations $s_{i j}$ to target $k$.

The values of every sequence must be normalized to be in the same order, because an inaccurate grey relational degree 
will be introduced by order variation of the data characterizing the factors.

The values of every sequence must be normalized to be in the same order, because an inaccurate grey relational degree will be introduced by order variation of the data characterizing the factors.

Definition 2.2 [12] Let $S=\left\{s_{i j}=\left(a_{i}, b_{j}\right) \mid a_{i} \in A, b_{j} \in B\right\}$ the effect vector of different situations $s_{i j}, i=1,2, \cdots, r$; $j=1,2, \cdots, t$ to target $k$ be

$u^{(k)}=\left(u_{11}^{(k)}, u_{12}^{(k)}, \cdots, u_{1 t}^{(k)} ; u_{21}^{(k)}, u_{22}^{(k)}, \cdots, u_{2 t}^{(k)} ; \cdots ; u_{r 1}^{(k)}, u_{r 2}^{(k)}, \cdots, u_{r t}^{(k)}\right)$, $k=1,2, \cdots, n$, the normalized sequences $\bar{u}^{(k)}$ by mean value can be derived as:

$u^{(k)}=\left(u_{11}^{(k)}, u_{12}^{(k)}, \cdots, u_{1 t}^{(k)} ; u_{21}^{(k)}, u_{22}^{(k)}, \cdots, u_{2 t}^{(k)} ; \cdots ; u_{r 1}^{(k)}, u_{r 2}^{(k)}, \cdots, u_{r t}^{(k)}\right)$, $k=1,2, \cdots, n$, the normalized sequences $\bar{u}^{(k)}$ by mean value can be derived as:

$\bar{u}^{(k)}=\left(\frac{u_{11}^{(k)}}{\bar{u}_{1}^{(k)}}, \frac{u_{12}^{(k)}}{\bar{u}_{1}^{(k)}}, \cdots, \frac{u_{1 t}^{(k)}}{\bar{u}_{1}^{(k)}} ; \frac{u_{21}^{(k)}}{\bar{u}_{2}^{(k)}}, \frac{u_{22}^{(k)}}{\bar{u}_{2}^{(k)}}, \cdots, \frac{u_{2 t}^{(k)}}{\bar{u}_{2}^{(k)}} ; \cdots ; \frac{u_{r 1}^{(k)}}{\bar{u}_{r}^{(k)}}, \frac{u_{r 2}^{(k)}}{\bar{u}_{r}^{(k)}}, \cdots, \frac{u_{r t}^{(k)}}{\bar{u}_{r}^{(k)}}\right)$

where $\bar{u}_{i}^{(k)}=\frac{1}{t} \sum_{j=1}^{t} u_{i j}^{(k)}, k=1,2, \cdots, n$.

GRA method was originally proposed by Deng [24] to analyze various relationships among the discrete data sets and make decision in multi-objective situation [31, 32]. The absolute degree of grey relation is applied to examine the direct and indirect relationships among the discrete data sets, which has been defined as follows:

Definition 2.3 Let effect vector of different situations $s_{i j}$ be $u_{i j}=\left(u_{i j}^{(1)}, u_{i j}^{(2)}, \cdots, u_{i j}^{(n)}\right), i=1,2, \cdots, r ; j=1,2, \cdots, t, \quad$ and the optimal vector of the targets be $u_{i_{0} j_{0}}=\left(u_{i_{0} j_{0}}^{(1)}, u_{i_{0} j_{0}}^{(2)}, \cdots, u_{i_{0} j_{0}}^{(n)}\right)$, then

$\varepsilon_{i j}=\frac{1+\left|s_{i j}\right|+\left|s_{i_{0} j_{0}}\right|}{1+\left|s_{i j}\right|+\left|s_{i_{0} j_{0}}\right|+\left|s_{i j}-s_{i_{0} j_{0}}\right|}$,

where

$s_{i j}=\sum_{k=2}^{n-1} u_{i j}^{(k)}(0)+\frac{1}{2} u_{i j}^{(n)}(0), s_{i_{0} j_{0}}=\sum_{k=2}^{n-1} u_{i_{0} j_{0}}^{(k)}(0)+\frac{1}{2} u_{i_{0} j_{0}}^{(n)}(0)$,

$u_{i j}^{(k)}(0)=u_{i j}^{(k)}-u_{i j}^{(1)}, u_{i_{0} j_{0}}^{(k)}(0)=u_{i_{0} j_{0}}^{(k)}-u_{i_{0} j_{0}}^{(1)}$,

we call $\varepsilon_{i j}(i=1,2, \cdots, r ; j=1,2, \cdots, t)$, illustrated in Eq. (2), the absolute degree of grey relation between $u_{i j}$ and $u_{i_{0} j_{0}}$.

\section{GREY RELATIONAL DECISION-MAKING METHOD BASED ON EVIDENCE THEORY}

The main procedure of grey relational decision-making is to first determine the ideal target sequence. Then, the absolute degree of grey relational between all comparability sequences and the ideal target sequence is calculated. Finally, we can sort these schemes according to the size of the grey absolute relational degree between the ideal target sequence and itself. Better water resources allocation scheme depends on higher grey relational degree. In fact, the important degrees of the decision targets are not the same, which needs us to determine the weight of the decision target. This paper further improves the algorithm of reliability of indexes and converts the original reliability of indexes into corresponding weights of indexes on the basis of evidence theory.

\subsection{Determining the Weight of the Decision Target Based on Evidence Theory}

If the credibility of a decision target is higher in the process of the optimization of water resources allocation schemes, it turns that this decision target should have received more attention [22], namely the weight of decision target can be represented by the credibility. Then, we figure out the weight of the decision target based on evidence theory which involves the following steps:

Step 1: Let $\Theta=\left\{A_{1}, A_{2}, \cdots, A_{t}\right\}=\left\{b_{1}, b_{2}, \cdots, b_{t}\right\}$ be the discernment frame consisting of water resources allocation schemes, $E=O=\left\{O_{1}, O_{2}, \cdots, O_{n}\right\}$ be an evidence set consisting of decision targets, $\left(m_{i}\left(A_{j}\right)\right)_{t \times n}=\left(\tilde{x}_{i j}\right)_{t \times n}$ be a matrix consisting of basic belief assignment (BBA) of different focal elements to different evidences, where $\left(\tilde{x}_{i j}\right)_{t \times n}$ is the normalized matrix of the decision target value matrix consisting of the values of decision targets to different evaluation schemes.

We can calculate the distance $d\left(m_{i}, m_{j}\right)$ between $\forall E_{i} \in E$ and $\forall E_{j} \in E$ according to the following Eq. (3) [17], then we have the distance matrix of decision targets as $D=\left(d\left(m_{i}, m_{j}\right)\right)_{n \times n}$.

$d\left(m_{i}, m_{j}\right)=\sqrt{\frac{1}{2}\left(\left\langle m_{i}, m_{i}\right\rangle+\left\langle m_{j}, m_{j}\right\rangle-2\left\langle m_{i}, m_{j}\right\rangle\right)}$

where $\left\langle m_{i}, m_{j}\right\rangle=\sum_{i=1}^{t} \sum_{j=1}^{t} m_{i}\left(A_{p}\right) m_{j}\left(A_{q}\right) D_{p q}, m_{i}$ is the BBA of the evidence $E_{i}$ to the focal element $A_{p}$, and $m_{j}$ is the $\mathrm{BBA}$ of the evidence $E_{j}$ to the focal element $A_{q}$, $D_{p q}=\left|A_{p} \cap A_{q}\right| /\left|A_{p} \cup A_{q}\right|, p, q=1,2, \cdots, t \quad$ is the similarity between $A_{p}$ and $A_{q}$.

Step 2: Distance and similarity of two evidences are a pair of reciprocal concepts, i.e., the less distance, the greater similarity, and vice versa. And if a piece of evidence is similar to other evidences, which indicates that the evidence is well supported by others, we can generally believe that the higher the support degree of a piece of evidence by others, the more reliable the evidence, and vice versa. Thus we can define absolute reliability of $m_{i}$ as 


$$
\begin{aligned}
& \operatorname{Crd}\left(m_{i}\right)=\max \left\{\frac{1}{n-1} \sum_{j=1, j \neq i}^{n} d\left(m_{i}, m_{j}\right)\right\} \\
& +\frac{1}{n}-\frac{1}{n-1} \sum_{j=1, j \neq i}^{n} d\left(m_{i}, m_{j}\right)
\end{aligned}
$$

Step 3: Normalizing by the following equation, we further obtain the relative reliability of $m_{i}$ as

$$
\omega_{i}=\operatorname{Crd}\left(m_{i}\right)=\frac{\operatorname{Crd}\left(m_{i}\right)}{\sum_{i=1}^{n} \operatorname{Crd}\left(m_{i}\right)}
$$

Then, the weight vector of decision targets is calculated as $W=\left(\omega_{1}, \omega_{2}, \cdots, \omega_{n}\right)$ by Eq. (5).

\subsection{The Comprehensive Decision-Making Method}

In the following, we introduce the grey decision-making method based on evidence theory. The flow diagram of calculation procedure of the method is shown in Fig. (1), and the method involves the following steps:

Step 1: Determine event set $A=\left\{a_{i} \mid i=1,2, \cdots, r\right\}$ and strategy set $B=\left\{b_{i} \mid i=1,2, \cdots, \mathrm{t}\right\}$, then we have corresponding situation set $S=\left\{s_{i j}=\left(a_{i}, b_{j}\right) \mid a_{i} \in A, b_{j} \in B\right\}$. The effect value $u_{i j}^{(k)}$ of different situations $s_{i j}, i=1,2, \cdots, r ; j=1,2, \cdots, t$ to the decision target $k$ just means different value of schemes to various decision targets as $u^{(k)}=\left(u_{11}^{(k)}, u_{12}^{(k)}, \cdots, u_{1 t}^{(k)} ; u_{21}^{(k)}, u_{22}^{(k)}, \cdots, u_{2 t}^{(k)} ; \cdots ; u_{r 1}^{(k)}, u_{r 2}^{(k)}, \cdots, u_{r t}^{(k)}\right)$, $k=1,2, \cdots, n$. To make effect vector in the same order, we normalize $u^{(k)}$ by Eq. (1). We still describe the normalized vector as $u^{(k)}$. Then, we have the effect vector of decision targets $\quad u_{i j}=\left(u_{i j}^{(1)}, u_{i j}^{(2)}, \cdots, u_{i j}^{(n)}\right), i=1,2, \cdots, r ; j=1,2, \cdots, t \quad$ of different situations $s_{i j}, i=1,2, \cdots, r ; j=1,2, \cdots, t$.

Step 2: Determine the weight vector of decision targets, then we can have the decision target weights by calculating the relative reliability of every decision target based on evidence theory as $W=\left(\omega_{1}, \omega_{2}, \cdots, \omega_{n}\right)$.

Step 3: Determine the vector of weighted mean value of situation sequences to diverse decision targets, then, we select the optimal vector based on these vectors according to the analysis results of the nature of the decision targets. The effect vector of weighted mean value of different situations $s_{i j}, i=1,2, \cdots, r ; j=1,2, \cdots, t \quad$ to the decision target $k$ is $\tilde{u}_{i j}=\left(w_{1} u_{i j}^{(1)}, w_{2} u_{i j}^{(2)}, \cdots, w_{n} u_{i j}^{(n)}\right), i=1,2, \cdots, r ; j=1,2, \cdots, t$.

The less the value of cost-type decision target, the better the scheme, and the greater the value of benefit-type decision target, the better the scheme. From the above analysis about the nature of decision target, we have the ideal target vector of the decision targets $\tilde{u}_{i_{0} j_{0}}=\left(w_{1} u_{i_{0} j_{0}}^{(1)}, w_{2} u_{i_{0} j_{0}}^{(2)}, \cdots, w_{n} u_{i_{0} j_{0}}^{(n)}\right)$.

Step 4: Calculate the absolute degree of grey relational $\varepsilon_{i j}(i=1,2, \cdots, r ; j=1,2, \cdots, t)$ between $\tilde{u}_{i j}$ and $\tilde{u}_{i_{0} j_{0}}$ by Eq. (2).

Step 5: According to $\max _{1 \leq i \leq r, 1 \leq j \leq t}\left\{\varepsilon_{i j}\right\}=\varepsilon_{i_{1} j_{1}}$, we can have that $\tilde{u}_{i_{1} j_{1}}$ is the optimal vector, namely $s_{i_{1} j_{1}}$ is the optimal situation of the known and $b_{j_{1}}$ is the optimal scheme.

Determine the effect vector of decision targets of different situation

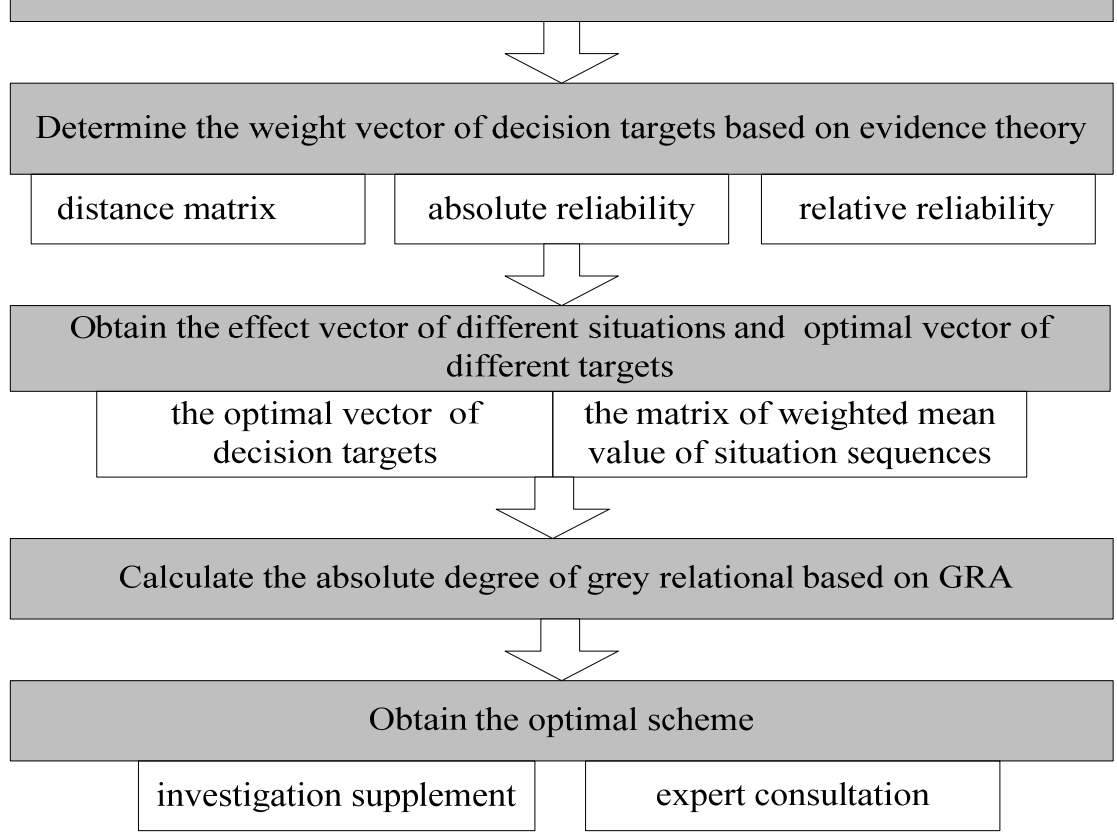

Fig. (1). Flow diagram of calculation procedure. 


\section{CASE STUDY}

To identify the validity and feasibility of the proposed method, we select water resources allocation schemes of Tianjin city in China as the case to study. By means of a great quantity of documents and data reading such as "countermeasure research about urban water supply security of Tianjin" and "mid-term and long-term planning of water supply of Tianjin", we obtain related data and find that the original analytical methods especially the methods of weight determination excessively depend on the expertise, which is relatively subjective. Hence, we apply the method described in this article to single out the favorable project. The process is as follows.

\subsection{General Situation and Research Value of Study Area}

Tianjin city is located in the northeast of North China Plain, and is the economic center of Circum-Bohai area as well. There are numbers of rivers, like mainstream of Haihe River, Yongding River, Beiyun River and Daqing River etc. The climate of this region is mainly affected by the monsoon, which results in uneven amount of precipitation of year and $60 \%-80 \%$ of rainfall appears in the flood period. Meanwhile the average rainfall of years increases by degrees from north to south. This extent of variation of precipitation of areas is between $560 \mathrm{~mm}$ and $720 \mathrm{~mm}$. While the population of permanent residents in Tianjin has exceeded ten million and the per capita possession of water resources is merely about $1 / 15$ of the national level. The problems such as serious shortage of water resources, uneven distribution among regions and excessive exploitation of deep groundwater have seriously restricted the development of local economy and society. Hence, rationalizing the allocation of water resources is a significant technique to solve the local conflicts of water resources. So we select Tianjin as the study area.

\subsection{Sets of Water Resources Allocation Schemes}

According to the society, economy and water conservancy project of Tianjin, we set up multiple water resources allocation measures. On the basis of principle of water resources allocation, namely satisfaction for water demand, satisfaction for water supply and optimization for the layout of the project, we select 8 well representative and feasible water resources allocation schemes by analysis, comparison and screening [9]. The schemes are shown in Table $\mathbf{1}$.

\subsection{Decision Target System of the Schemes}

According to the existing basic datum and the available research results of comprehensive decision target system of water resources, we establish the decision target system of water resources allocation schemes in view of four aspects, namely social rationality, economic rationality, ecological rationality and efficiency rationality. Then, we obtain the values of decision targets of water resources allocation schemes of Tianjin in 2010 by the secondary data and the results of further calculations [9] which have been shown in Table 2.

\subsection{Decision-Making Procedures}

In the following, we shall utilize the grey decision-making method based on evidence theory to select the optimal scheme. The decision-making process is divided into five steps. The procedure is as follows:

Step 1: Let the optimization of water resources allocation schemes of Tianjin in 2010 be an event $a_{1}$, then we have the event set $A=\left\{a_{1}\right\}$. Let 8 schemes of water resources allocation of Tianjin be the strategy $b_{i}, i=1,2, \cdots, 8$, then we have the strategy set $B=\left\{b_{1}, b_{2}, \cdots, b_{8}\right\}$, so the corresponding situation set is $S=\left\{s_{i j}=\left(a_{i}, b_{j}\right) \mid a_{i} \in A, b_{j} \in B\right\}=\left\{s_{11}, s_{12}, \cdots, s_{18}\right\}$.

Table 1. Water Resources Allocation Schemes of Tianjin in 2010

\begin{tabular}{|l|c|c|c|c|c|c|c|c|}
\hline \multicolumn{1}{|c|}{ Scheme } & $\mathbf{1}$ & $\mathbf{2}$ & $\mathbf{3}$ & $\mathbf{4}$ & $\mathbf{5}$ & $\mathbf{6}$ & $\mathbf{7}$ & $\mathbf{8}$ \\
\hline \hline Water diversion project from Luanhe River to Tianjin & $\sqrt{ }$ & $\sqrt{ }$ & $\sqrt{ }$ & $\sqrt{ }$ & $\sqrt{ }$ & $\sqrt{ }$ & $\sqrt{ }$ & $\sqrt{ }$ \\
\hline The middle line of the south-to-north water transfer project & $\sqrt{ }$ & $\sqrt{ }$ & $\sqrt{ }$ & $\sqrt{ }$ & $\sqrt{ }$ & $\sqrt{ }$ & $\sqrt{ }$ & $\sqrt{ }$ \\
\hline East-route of south-to-north water transfer project & $\sqrt{ }$ & $\sqrt{ }$ & $\sqrt{ }$ & $\sqrt{ }$ & $\sqrt{ }$ & $\sqrt{ }$ & $\sqrt{ }$ & $\sqrt{ }$ \\
\hline General level of water-saving & $\sqrt{ }$ & $\sqrt{ }$ & $\sqrt{ }$ & $\sqrt{ }$ & & & & \\
\hline High level of saving water & & & & & $\sqrt{ }$ & $\sqrt{ }$ & $\sqrt{ }$ & $\sqrt{ }$ \\
\hline Present amount of recycle sewage & $\sqrt{ }$ & $\sqrt{ }$ & & & $\sqrt{ }$ & $\sqrt{ }$ & & \\
\hline Increased amount of recycle sewage & & & $\sqrt{ }$ & $\sqrt{ }$ & & & $\sqrt{ }$ & $\sqrt{ }$ \\
\hline Present amount of utilization of seawater & $\sqrt{ }$ & & $\sqrt{ }$ & & $\sqrt{ }$ & & $\sqrt{ }$ & \\
\hline Increased amount of utilization of seawater & & $\sqrt{ }$ & & $\sqrt{ }$ & & $\sqrt{ }$ & & $\sqrt{ }$ \\
\hline
\end{tabular}


Table 2. Values of Decision Targets of Water Resources Allocation Schemes

\begin{tabular}{|c|c|c|c|c|c|c|c|c|c|}
\hline \multirow{2}{*}{ Society } & Regional water deficient ratio & 29.69 & 26.26 & 21.77 & 18.34 & 22.28 & 17.82 & 11.97 & 7.5 \\
\hline & Agricultural water deficient ratio & 45.36 & 45.36 & 35.05 & 35.05 & 31.11 & 31.11 & 18.12 & 18.12 \\
\hline \multirow{2}{*}{ Economic } & Industrial output per cubic meter of water consumption & 1157.76 & 1109.10 & 1112.67 & 1040.76 & 1204.84 & 1145.05 & 1168.91 & 1111.11 \\
\hline & Investment of hydraulic project & 34.05 & 58.63 & 49.30 & 73.48 & 60.01 & 84.19 & 80.86 & 99.04 \\
\hline Ecology & Recycle rate of sewage & 3.6 & 3.6 & 8.29 & 8.29 & 3.6 & 3.6 & 8.29 & 8.29 \\
\hline \multirow[b]{2}{*}{ Efficiency } & Recycle rate of industrial water & 80 & 80 & 80 & 80 & 85 & 85 & 85 & 85 \\
\hline & Efficiency of agricultural water & 0.57 & 0.57 & 0.57 & 0.57 & 0.75 & 0.75 & 0.75 & 0.75 \\
\hline
\end{tabular}

The effect value $u_{i j}^{(k)}$ of different situations $s_{i j}, i=1 ; j=1,2, \cdots, 8$ to decision target $k$ just means different value of schemes to various decision targets presented in Table 2. Then the mean value $u^{(k)}, k=1,2, \cdots, 10$ can be normalized by Eq. (1) as follows:

$U=\left[\begin{array}{l}u^{(1)} \\ u^{(2)} \\ u^{(3)} \\ u^{(4)} \\ u^{(5)} \\ u^{(6)} \\ u^{(7)} \\ u^{(8)} \\ u^{(9)} \\ u^{(10)}\end{array}\right]=\left[\begin{array}{cccccccc}1.53 & 1.35 & 1.12 & 0.94 & 1.15 & 0.92 & 0.62 & 0.39 \\ 2.56 & 1.00 & 1.44 & 0.00 & 1.95 & 0.28 & 0.76 & 0.00 \\ 1.40 & 1.40 & 1.08 & 1.08 & 0.96 & 0.96 & 0.56 & 0.56 \\ 1.02 & 0.97 & 0.98 & 0.92 & 1.07 & 1.01 & 1.03 & 0.98 \\ 0.75 & 1.02 & 0.94 & 1.13 & 0.85 & 1.13 & 1.06 & 1.00 \\ 0.5 & 0.87 & 0.73 & 1.09 & 0.89 & 1.25 & 1.20 & 1.47 \\ 0.61 & 0.61 & 1.39 & 1.39 & 0.61 & 0.61 & 1.39 & 1.39 \\ 0.97 & 0.97 & 0.97 & 0.97 & 1.03 & 1.03 & 1.03 & 1.03 \\ 0.86 & 0.86 & 0.86 & 0.86 & 1.14 & 1.14 & 1.14 & 1.14 \\ 1.20 & 1.20 & 1.20 & 1.20 & 0.80 & 0.80 & 0.80 & 0.80\end{array}\right]$

Then we have the effect vector of decision targets $u_{1 j}=\left(u_{1 j}^{(1)}, u_{1 j}^{(2)}, \cdots, u_{1 j}^{(10)}\right), j=1,2, \cdots, 8$ of different situations $s_{1 j}(j=1,2, \cdots, 8)$.

Step 2: Determine the weight vector of decision targets. We have the decision target set as $E=O=\left\{O_{1}, O_{2}, \cdots, O_{10}\right\}$. Hence, we can obtain the normalized matrix as $\left(m_{i}\left(A_{j}\right)\right)_{t \times n}=\left(\tilde{x}_{i j}\right)_{t \times n}$. By Eq. (3) in Section 3, we can get the distance matrix of the decision targets:

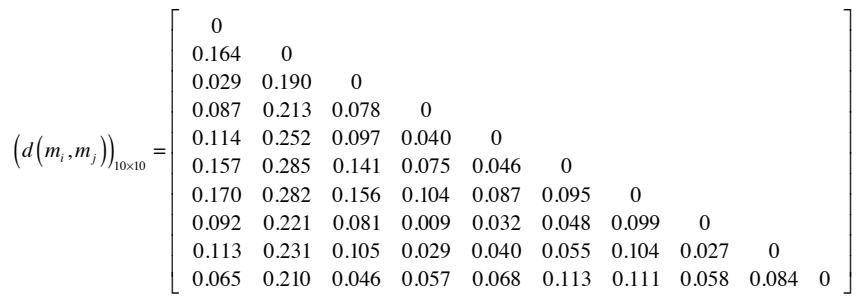

By Eq. (4), the absolute reliability as $\operatorname{Crd}\left(m_{j}\right), j=1,2, \cdots, 10$ can be calculated as follows:
$\left(\operatorname{Crd}\left(m_{1}\right), \operatorname{Crd}\left(m_{2}\right), \cdots, \operatorname{Crd}\left(m_{10}\right)\right)$

$=\left(\begin{array}{l}0.218,0.100,0.225,0.251,0.241,0.224, \\ 0.193,0.254,0.240,0.237\end{array}\right)$

Finally, we get the weight vector of decision targets as $W$ that are calculated by Eq. (5) as follows:

$(0.100,0.046,0.103,0.115,0.110,0.102,0.089,0.116,0.110,0.109)$

Step 3: From the above analysis, the matrix of weighted mean value of situation sequences to diverse decision targets can be derived as follows:

$\tilde{\mathrm{U}}=\left[\begin{array}{c}\omega_{1} u^{(1)} \\ \omega_{2} u^{(2)} \\ \omega_{3} u^{(3)} \\ \omega_{4} u^{(4)} \\ \omega_{5} u^{(5)} \\ \omega_{6} u^{(6)} \\ \omega_{7} u^{(7)} \\ \omega_{8} u^{(8)} \\ \omega_{9} u^{(9)} \\ \omega_{10} u^{(10)}\end{array}\right]=\left[\begin{array}{ccccccccc}0.15 & 0.13 & 0.11 & 0.09 & 0.11 & 0.09 & 0.06 & 0.04 \\ 0.12 & 0.05 & 0.07 & 0.00 & 0.09 & 0.01 & 0.03 & 0.00 \\ 0.14 & 0.14 & 0.11 & 0.11 & 0.10 & 0.10 & 0.06 & 0.06 \\ 0.12 & 0.11 & 0.11 & 0.11 & 0.12 & 0.12 & 0.12 & 0.11 \\ 0.08 & 0.11 & 0.10 & 0.12 & 0.09 & 0.12 & 0.12 & 0.11 \\ 0.05 & 0.09 & 0.07 & 0.11 & 0.09 & 0.13 & 0.12 & 0.15 \\ 0.05 & 0.05 & 0.12 & 0.12 & 0.05 & 0.05 & 0.12 & 0.12 \\ 0.11 & 0.11 & 0.11 & 0.11 & 0.12 & 0.12 & 0.12 & 0.12 \\ 0.10 & 0.10 & 0.10 & 0.10 & 0.13 & 0.13 & 0.13 & 0.13 \\ 0.13 & 0.13 & 0.13 & 0.13 & 0.09 & 0.09 & 0.09 & 0.09\end{array}\right]$

Since the decision targets such as regional water deficient ratio, industrial water deficient ratio, agricultural water deficient ratio, investment of hydraulic project and leak rate of urban water supply network belong to the cost-type decision target, the less the value of the decision target, the better will be the project. While the decision targets such as industrial output per cubic meter of water consumption, growth rate of industrial added value, recycle rate of sewage and efficiency of agricultural water belong to the benefittype decision target, the greater the value of the decision target, the better will be the project. Taking into consideration the social rationality, economic rationality and efficiency rationality based on this conclusion, the optimal vectors of decision targets are

$\tilde{u}_{1 j_{0}}^{s}=(0.04,0,0.06), \tilde{u}_{1 j_{0}}^{e}=(0.12,0.12,0.05), \tilde{u}_{j_{0}}^{f}=(0.12,0.13,0.09)$, 
respectively. Because ecology is calculated by recycle rate of sewage index, and this index belongs to the benefit-type decision target, water resources allocation of scheme 3, 4, 7 and 8 is better than that of scheme 1,2, 5 and 6 in terms of ecological rationality. And, we can obtain the optimal vector of decision targets from social rationality, economic rationality, ecological rationality and efficiency rationality aspects as follow:

$\tilde{u}_{1 j_{0}}=(0.04,0,0.06,0.12,0.12,0.05,0.12,0.12,0.13,0.09)$

The matrix of weighted mean value of situation sequences to diverse decision targets corresponding to $s_{i j}(i=1 ; j=1,2, \cdots, 8)$ can be derived as $\tilde{U}^{T}$.

Step 4: Calculate the absolute degree of grey relational.

Taking society for considered, calculate the absolute degree of grey relational $\varepsilon_{i j}^{s}(i=1 ; j=1,2, \cdots, 8)$ between $\tilde{u}_{1 j}^{s}$ and $\tilde{u}_{1 j_{0}}^{s}$ by Eq. (2), where $\left(\tilde{u}_{11}^{s}, \tilde{u}_{12}^{s}, \cdots, \tilde{u}_{18}^{s}\right)^{T}=\left(\omega_{1} u^{(1)}, \omega_{2} u^{(2)}, \omega_{3} u^{(3)}\right)$. Then, we have

$\varepsilon_{11}^{s}=0.995, \varepsilon_{12}^{s}=0.961, \varepsilon_{13}^{s}=0.991, \varepsilon_{14}^{s}=0.957$,

$\varepsilon_{15}^{s}=0.995, \varepsilon_{16}^{s}=0.961, \varepsilon_{17}^{s}=1.000, \varepsilon_{18}^{s}=1.000$.

The same procedure may be easily adapted to obtain the absolute degree of grey relational as follows:

$\varepsilon_{11}^{e}=0.982, \varepsilon_{12}^{e}=0.977, \varepsilon_{13}^{e}=0.991, \varepsilon_{14}^{e}=0.963$,

$\varepsilon_{15}^{e}=0.995, \varepsilon_{16}^{e}=0.963, \varepsilon_{17}^{e}=0.967, \varepsilon_{18}^{e}=0.950$.

$\varepsilon_{11}^{f}=0.985, \varepsilon_{12}^{f}=0.985, \varepsilon_{13}^{f}=0.985, \varepsilon_{14}^{f}=0.985$,

$\varepsilon_{15}^{s}=1.000, \varepsilon_{16}^{s}=1.000, \varepsilon_{17}^{f}=1.000, \varepsilon_{18}^{f}=1.000$.

Calculate the absolute degree of grey relational $\varepsilon_{i j}(i=1 ; j=1,2, \cdots, 8)$ between $\tilde{u}_{1 j}$ and $\tilde{u}_{1 j_{0}}$ by Eq. (2).

$$
\begin{aligned}
& \varepsilon_{11}=0.68, \varepsilon_{12}=0.71, \varepsilon_{13}=0.75, \varepsilon_{14}=0.81, \\
& \varepsilon_{15}=0.74, \varepsilon_{16}=0.80, \varepsilon_{17}=0.96, \varepsilon_{18}=0.96 .
\end{aligned}
$$

\section{Step 5: Obtain the optimal scheme:}

$$
\text { According to } \max _{i=1,1 \leq j \leq 8}\left\{\varepsilon_{i j}^{s}\right\}=\varepsilon_{17}=\varepsilon_{18}=1 \text {, we can see that }
$$
$\tilde{u}_{17}^{s}$ and $\tilde{u}_{18}^{s}$ are the optimal real vectors, namely $s_{17}$ and $s_{18}$ are the optimal situations of the known. Hence we can get that project 7 and 8 are optimal schemes from social rationality aspect. According to $\max _{i=1,1 \leq j \leq 8}\left\{\varepsilon_{i j}^{e}\right\}=\varepsilon_{15}=0.995$, we can obtain project 5 is optimal scheme in term of social rationality. According to $\max _{i=1,1 \leq j \leq 8}\left\{\varepsilon_{i j}^{e}\right\}=\varepsilon_{15}=\varepsilon_{16}=\varepsilon_{17}=\varepsilon_{18}=1$, we have the optimal scheme are scheme 5, 6, 7 and 8 in term of social rationality. From step 3 in case study, we have that scheme $3,4,7$ and 8 are better than the rest in views of ecological rationality. Hence, taking the various rationalities above for considered, we can conclude that the optimal plan focus on the scheme 7 and 8 .

According to $\max _{i=1,1 \leq j \leq 8}\left\{\varepsilon_{i j}\right\}=\varepsilon_{17}=\varepsilon_{18}=0.96$, we can see that project 7 and 8 are preferred to be selected from the alternatives on the basis of the above method. While the consequences of the two selected project are the same, we need rank them combining with the specific circumstance and growing trend of Tianjin. By comparing the two projects (see Table 1), we can find that the distinction is merely whether to increase the amount of utilization of seawater. Because the verge of Bohai Sea, Tianjin abounds in seawater resources and technical support. Some sustainable development strategies are recommended to solve the problem of water shortage in this area. In view of the social and economic status of Tianjin in the future, improving water use efficiency or water diversion among areas to meet future water demand may be not enough. If we could turn saline water into daily water used in production or living, it will be able to greatly enhance the water supply capacity as well as save scarce fresh water resources effectively. Hence, we take project 8 as the recommendation of water resources allocation scheme of Tianjin in 2010 on the basis of the above analysis.

\section{CONCLUSIONS}

The scheme selection of water resources allocation is a multi-objective decision-making procedure, which is plagued by uncertain and incomplete information. So we regarded it as a multi-objective grey relational decision-making procedure. In fact, the important degrees of the decision targets are not the same, forcing us to determine the weight of the decision target. The traditional weight determination methods focus too much on the expert scoring and opinions. To solve this problem effectively, this paper further improves the algorithm of reliability of indexes, and converts the original reliability of indexes into corresponding weights of indexes based on evidence theory. Then, this paper proposes a decision-making method, integrating evidence theory and grey relational decision-making method, wherein evidence theory is used to determine the weight of each decision target and grey relational decision-making method is applied to determine the optimal real vector or vectors. Finally, results of case study in Tianjin indicate the feasibility and validity of the proposed method.

\section{CONFLICT OF INTEREST}

The authors confirm that this article content has no conflict of interest.

\section{ACKNOWLEDGEMENTS}

This work was supported by the National Natural Science Foundation (Grant No. 41271537) and the key program of the National Social Science Foundation (Grant No. 12\&ZD214), Ministry of Education (Grant No. 11 YJA870007), P.R. China. 


\section{REFERENCES}

[1] B. George, H. Malano, B. Davidson, P. Hellegers, L. Bharati, and S. Massuel, "An integrated hydro-economic modeling framework to evaluate water allocation strategies I: Model development", Agric. Water Manage., vol. 98, pp. 733-746, 2011.

[2] Q. J. Dong, S. L. Chen, L. B. Zhang, and X. J. Wang, "Comprehensive evaluation of water resources allocation alternatives based on D-S evidence theory", Math. Pract. Theory., vol. 41, pp. 26-30, 2009

[3] R. Farmani, D. A. Savic, and G. A. Walters, "Evolutionary multiobjective optimization in water distribution network design", Eng. Optim., vol. 37, pp.167-183, 2005.

[4] J. B. Kollat, and P. M. Reed, "Comparing state-of-the-art evolutionary multi-objective algorithms for long-term groundwater monitoring design", Adv. Water Resour., vol. 29, pp.792-807, 2006.

[5] J. R. Kasprzyk., P. M. Reed, B. Kirsch, and G. Characklis, "Manyobjective de Novo water supply portfolio planning under deep uncertainty", Environ. Model. Softw., vol. 34, pp. 87-104, 2012.

[6] P. M. Reed, and J. B. Kollat, "Save now, pay later? Multi-period manyobjective groundwater monitoring design given systematic model errors and uncertainty", Adv. Water Resour., vol. 34, pp.87104, 2012.

[7] W. R. Wang, and M. Z. Tu, "Calculating of proportion based on analytic hierarchy process in basin water allocation", J. Tongji Univ. (Nat. Sci.), vol. 33, pp. 1133-1136, 2005.

[8] W. X. Guo, Z. Q. Xia, H. X. Wan, J. X. Xu, and H. S. Xu, "Comprehensive evaluation of reasonable allocation schemes of water resources based on fuzzy matter-element model", $J$. Irrigation Drainage, vol. 26, pp. 75-78, 2007.

[9] J. X. Yu, X. G. Jiang, and J. J. Lian, "Comprehensive evaluation model for optimal deployment of water resources based on fuzzy theory and information entropy", J. Hydraulic Eng., vol. 40, pp. 729-735, 2009.

[10] L. N. Zhang, F. P. Wu, and P. Jia, "Grey evaluation model based on reformative triangular whitenization weight function and its application in water rights allocation system", Open Cybern. Syst. J., vol. 7, pp 1-10, 2013

[11] Y. Ding, C. Y. Ling, and B. H. Fang, "Application of multireservoir flood control systems based on evidence theory", Adv. Water Sci., vol. 18, No14, pp 591-597, 2007.

[12] S. F. Liu, Y. G. Dang, and Z. G. Fang, Grey system theory and its applications. Science Press: Beijing, 2010.

[13] W. G. Wu, "Grey relational analysis method for 2-tuple linguistic multiple attribute group decision making with incomplete weight information”, Expert Syst. Appl., vol. 38, pp. 4824-4828, 2011.

[14] K. H. Chang, Y. C. Chang, and I. T. Tsai, "Enhancing FMEA assessment by integrating grey relational analysis and the decision making trial and evaluation laboratory approach", Eng. Fail. Anal., vol. 31, pp. 211-224, 2013.

[15] A. P. Dempster, "Upper and lower probabilities induced by a multivalued mapping", Ann. Math. Stat., vol. 38, pp. 325-339, 1967.

[16] A. P. Dempster, "A generalization of Bayesian inference”, J. Roy. Stat. Soc., vol. B30, pp. 205-247, 1968.

[17] G. Shafer, A Mathematical Theory of Evidence. Princeton University Press: NJ, 1976.

[18] C. K. Murphy, "Combining belief functions when evidence conflicts", Decis. Support Syst., vol. 29, pp. 1-9, 2000.

[19] A. L. Jousselme, D. Grenier, and Éloi Bossé, "A new distance between two bodies of evidence", Inform. Fus., vol. 2, pp. 91-101, 2001

[20] S. L. Yang, W. K. Zhu, and M. L. Ren, "Combination theory and method for interrelated evidences based on optimal adjustment coefficient", J. Manage. Sci., vol. 6, pp. 12-16, 2003.

[21] Y. Deng, W. K. Shi, Z. F. Zhu, and Q. Liu, "Combining belief functions based on distance of evidence", Decis. Support Syst., vol. 38, pp. 489- 493, 2004.

[22] K. H. Guo, and W. L. Li, "Combination rule of D-S evidence theory based on the strategy of cross merging between evidences", Expert Syst. Appl., vol. 38, pp. 13360-13366, 2011.

[23] J. L. Deng, The basic methods of grey system. Huazhong University of Technology Press: Wuhan, China, 1988.

[24] J. L. Deng, "Introduction to grey system theory", J. Grey Syst. , vol. 1, pp. 1-24, 1989.

[25] J. L. Deng, Grey system theory. Huazhong University of Science \& Technology Press: Wuhan, China, 2002.

[26] J. J. Zhang, D. S. Wu, and D. L. Olson, "The method of grey related analysis to multiple attribute decision making problems with interval numbers", Math. Comput. Model., vol. 42, pp. 991998, 2005. [27] D. L. Olson, and D. S. Wu, "Simulation of fuzzy multiattribute models for grey relationships", Eur J. Oper Res., vol. 175, pp. 111-120, 2006.

[28] G. D. Li, D. Yamaguchi, and M. Nagai, "A grey-based decisionmaking approach to the supplier selection problem", Math. Comput. Model., vol. 46, pp. 573-581, 2007.

[29] Y. Y. Kuo, T. H. Yang, and G. W. Huang, "The use of grey relational analysis in solving multiple attribute decision-making problems", Comput. Ind. Eng., vol. 55, pp. 80-93, 2008.

[30] D. S. Wu, "Supplier selection in a fuzzy group decision making setting: A method using grey related analysis and Dempster-Shafer theory", Expert Syst. Appl., vol. 36, pp. 8892-8899, 2009.

[31] X. P. Xiao, Z. M. Song, and F. Li, Grey technology and its application. China Science Press: Beijing, China, 2005.

[32] C. Y. Kung, T. M. Yan, and C. C. Huang, "Using grey statistic method to evaluate the optimal distribution for strategic resources in medium and small enterprise", In: IEEE International Conference on Systems, Man and Cybernetics (SMC), Singapore, vol. 1-6, pp. 2865-2870, 2008

(c) Wu et al.; Licensee Bentham Open.

This is an open access article licensed under the terms of the Creative Commons Attribution Non-Commercial License (http://creativecommons.org/licenses/ by-nc/3.0/) which permits unrestricted, non-commercial use, distribution and reproduction in any medium, provided the work is properly cited. 